\title{
Selective depletion of macrophages reveals distinct, opposing roles during liver injury and repair
}

\author{
Jeremy S. Duffield, ${ }^{1,2}$ Stuart J. Forbes, ${ }^{3}$ Christothea M. Constandinou, ${ }^{4}$ Spike Clay, ${ }^{1}$ \\ Marina Partolina, ${ }^{5}$ Srilatha Vuthoori, ${ }^{6}$ Shengji Wu, ${ }^{7}$ Richard Lang, ${ }^{8}$ and John P. Iredale ${ }^{4}$
}

${ }^{1}$ Medical Research Council Centre for Inflammation Research, University of Edinburgh, Edinburgh, United Kingdom. 2Renal Division, Brigham and Women's Hospital, Harvard Institutes of Medicine, Boston, Massachusetts, USA. ${ }^{3}$ Department of Medicine, St. Mary's Hospital, Imperial College, London, United Kingdom. ${ }^{4}$ Division of Infection Inflammation and Repair, University of Southampton, United Kingdom. 5epartments of Radiation Oncology and Cell Biology, New York University School of Medicine, First Avenue, New York, New York, USA. ${ }^{6}$ Regeneron Pharmaceuticals, Tarrytown, New York, USA. ${ }^{7}$ Rodman and Renshaw, LLC, New York, New York, USA. ${ }^{8 D i v i s i o n}$ of Developmental Biology and Department of Ophthalmology, Children's Hospital Research Foundation, Cincinnati, Ohio, USA.

\begin{abstract}
Macrophages perform both injury-inducing and repair-promoting tasks in different models of inflammation, leading to a model of macrophage function in which distinct patterns of activation have been proposed. We investigated macrophage function mechanistically in a reversible model of liver injury in which the injury and recovery phases are distinct. Carbon tetrachloride-induced liver fibrosis revealed scar-associated macrophages that persisted throughout recovery. A transgenic mouse (CD11b-DTR) was generated in which macrophages could be selectively depleted. Macrophage depletion when liver fibrosis was advanced resulted in reduced scarring and fewer myofibroblasts. Macrophage depletion during recovery, by contrast, led to a failure of matrix degradation. These data provide the first clear evidence that functionally distinct subpopulations of macrophages exist in the same tissue and that these macrophages play critical roles in both the injury and recovery phases of inflammatory scarring.
\end{abstract}

\section{Introduction}

Macrophages feature prominently at diverse sites of inflammation and have been linked to the process of inflammation and repair, demonstrating a repertoire of activities that include regulating inflammatory cells, tissue debridement, cell killing, recruiting and activating myofibroblasts, and regulating spontaneous recovery of fibrosis in physiological or aberrant wound healing (1-6). In response to injury, cells of mesenchymal origin transdifferentiate into myofibroblasts, migrate, and generate the matrix components of scar tissue $(7,8)$. Myofibroblasts also have the capacity to express MMPs and tissue inhibitors of metalloproteinase (TIMPs), through which they regulate degradation of matrix components (9). The precise role of macrophages at the site of injury is unclear $(10,11)$, but they are known from in vitro experiments to generate a diverse array of agents that regulate the degradation of matrix $(7,10,12,13)$.

Recent cell surface phenotyping studies suggest that distinct macrophage populations exist. For example, the hemoglobin scavenger receptor CD163 is expressed by a subpopulation of macrophages at inflamed sites (14). Likewise, pattern recognition receptors such as dectin-1 and mannose receptors are highly expressed only in subsets of macrophages in inflamed tissue (15). To make sense of this diversity, 2 forms of inflammatory

Nonstandard abbreviations used: aa-M, alternatively activated macrophage; BTG Brewer's thioglycollate; $\mathrm{CCl}_{4}$, carbon tetrachloride; DT, diphtheria toxin; DT ${ }^{\text {mut }}$, mutant DT; DTR, DT receptor; hbEGF, heparin-binding EGF; hpf, high-power field; HSC, hepatic stellate cell; SAM, scar-associated macrophage; TIMP, tissue inhibitor of metalloproteinase.

Conflict of interest: J.P. Iredale has undertaken paid consultancy work advising the following companies on the design of noninvasive means of monitoring liver fibrosis: Pfizer, Hepcgen, and Ferring.

Citation for this article: J. Clin. Invest. 115:56-65 (2005).

doi:10.1172/JCI200522675. macrophages have been proposed: the classically activated macrophage and the alternatively activated macrophage (aa-M) (11). The former, activated by $\mathrm{T}_{\mathrm{H}} 1$ lymphokines, bacterial and fungal cell wall components, or degraded matrix (e.g., hyaluronic acid), liberates proinflammatory cytokines and chemokines and is predominantly lytic to matrix components $(16,17)$. The aa-M is activated by $\mathrm{T}_{\mathrm{H}} 2$ lymphokines, including interleukin-4, as well as apoptotic cells and corticosteroids, and produces anti-inflammatory cytokines including interleukin-10 and TGF- $\beta$. When cultured with myofibroblasts, aa-Ms promote complex matrix deposition $(11,13$, 18-20). However, these phenotypes have been defined predominantly in tissue culture models and may not reflect the complexity of macrophage function in vivo. In an injured tissue, macrophages appear to display features of both the proinflammatory and alternative activation programs $(18,20-23)$.

We set out to define the role of macrophages in a well-described and defined model of liver injury induced by carbon tetrachloride $\left(\mathrm{CCl}_{4}\right)$ in rodents in which inflammation and fibrosis occur. With iterative injury ( 3 months in mice, 1 month in rats), extensive scarring develops as indicated by transdifferentiation of hepatic stellate cells (HSCs) into myofibroblasts (known as activated HSCs), intense myofibroblast proliferation, and progressive laying down of complex polymeric matrix components (7). Following cessation of $\mathrm{CCl}_{4}$ injections, the scarring resolves completely (7). These distinct phases of injury, repair, and resolution make this an ideal model for studying injury- and repair-associated macrophages.

Here we show, using conditional macrophage depletion, that scarassociated macrophages (SAMs) are essential for normal injury and recovery responses. Macrophage depletion in mice during injury was associated with a dramatic loss of myofibroblast-like HSCs and resulted in extensive loss of matrix components. Depletion during the recovery phase, however, attenuated matrix degradation, partic- 


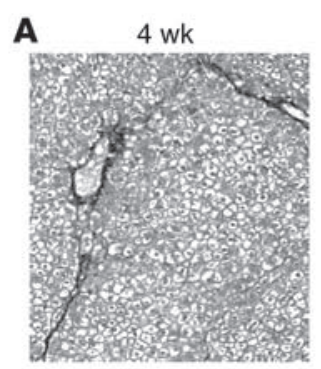

B

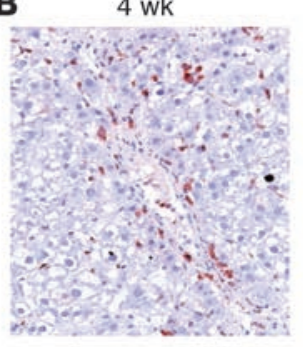

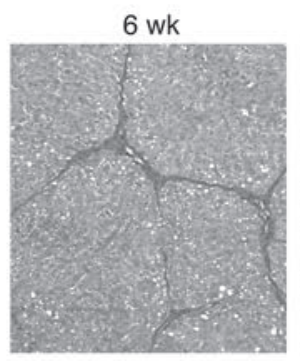

6 wk

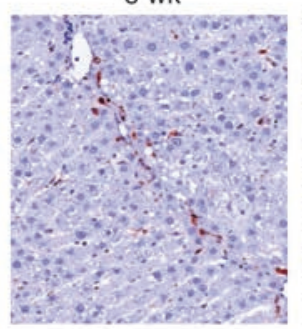

12 wk

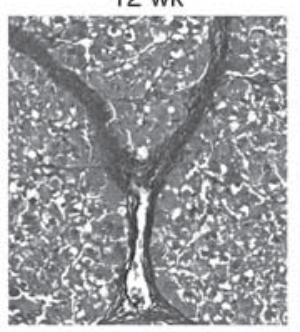

12 wk

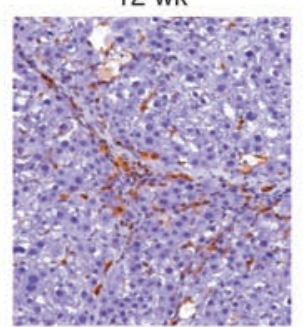

12 wk, 28 d recovery

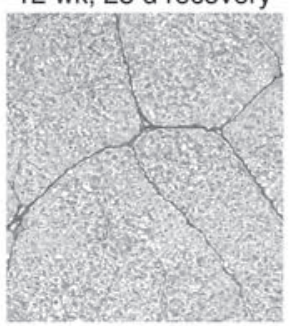

12 wk, 28 d recovery

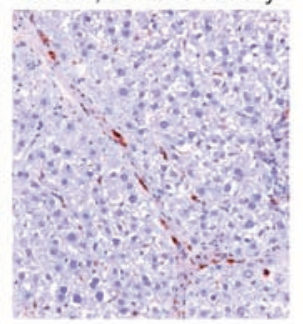

C

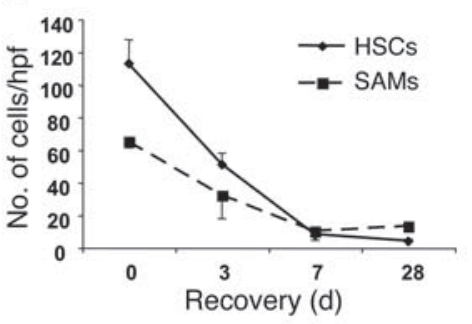

Figure 1

The relationship between SAMs, collagenous bands, and $\mathrm{HSC}$ during $\mathrm{CCl}_{4}$ injury and recovery in the Sprague-Dawley rat. (A) Sirius red staining (magnification, $\times 100$ ) of liver for collagenous bands at 4,6 , and 12 weeks of disease, and following 28 days of recovery after 12 weeks of injury. (B) ED-1 macrophages (magnification, $\times 100$ ) are associated with scar tissue after 4, 6, and 12 weeks of disease, and following 28 days of recovery after 12 weeks of injury. (C) Graph of SAMs and $\alpha$-SMA-positive HSCs at different stages of recovery from $\mathrm{CCl}_{4}$-induced fibrosis (4 weeks intoxication). Note the rapid decline in HSCs in the early phase of recovery.

ularly perisinusoidal fibrosis. These data define 2 distinct activities of macrophages with opposite but complementary functions.

\section{Results}

Macrophages are associated with liver fibrosis during injury and repair. In order to determine the role of macrophages in liver injury and repair, we induced fibrosis (4 weeks of $\mathrm{CCl}_{4}$ ), cirrhosis (12 weeks of $\mathrm{CCl}_{4}$ ), and spontaneous recovery following both fibrosis and cirrhosis in rats as previously described $(7,24)$. Liver sections were stained for markers of collagen, macrophages, and activated HSCs (Figure 1). At all stages of progressive fibrosis and cirrhosis, SAMs were found in significant numbers. SAMs were found within and apposed to the bands. In particular, the perisinusoidal fibrosis was rich in SAMs (Figure 1B). SAMs were also found to be associated with resolving areas of fibrosis in spontaneous recovery in both the fibrotic and cirrhotic models. Whereas over 28 days of spontaneous recovery, fibrosis completely resolved after 4 weeks of $\mathrm{CCl}_{4}$ intoxication, in spontaneous recovery from 12 weeks of cirrhosis, the perisinusoidal fibrosis had completely resolved, but the residual linking fibrotic septa persisted and continued to be associated with SAMs (Figure 1, B and C).

To evaluate the relationship and dynamics of the populations of myofibroblast-like activated HSCs and macrophages during spontaneous resolution of fibrosis, we stained sections at time points during spontaneous recovery from 4 weeks of fibrosis and counted both HSCs that stained positive for $\alpha$-SMA and SAMs that stained positive for ED-1 (8) (Figure 1C). A very close relationship between the 2 populations of cells was noted. During the first 7 days of recovery, $89 \% \pm 6 \%$ of HSCs disappeared, whereas $60 \% \pm 5 \%$ of SAMs disappeared. The close correlation between the numbers of SAMs and HSCs suggests an interdependence.

A model for selective depletion of macrophages. To generate a system in which macrophage function could be studied in vivo, we took advantage of a conditional ablation system mediated by diphthe- ria toxin $(\mathrm{DT})$ receptor $(25,26)$. This system relies on the fact that the mouse DT receptor (heparin-binding EGF; hbEGF) binds DT poorly compared with the human and simian molecules (27). Thus, transgenic expression of the human DT receptor (DTR) confers sensitivity to DT and permits ablation in vivo when DT is injected.

Six transgenic mouse lines were generated using the CD11b-DTR construct (Figure $2 \mathrm{~A}$ ) that uses the $C D 11 b$ gene regulatory elements (28) for macrophage-specific expression of a DTR molecule fused with GFP. Using an RT-PCR assay, we showed that transgenic mouse-derived BM macrophages (6) expressed the macrophagespecific gene F4/80 as expected (Figure 2B). Two out of 6 transgenic lines also showed expression of the transgene, with line 34 showing the highest level (see Figure 2C for positive and negative examples). As a result, line 34 was expanded for further investigation and is referred to hereafter as CD11b-DTR. As a test of ablation specificity, we performed i.p. injections of DT and examined, using FACS analysis, the effects on $\mathrm{CD}^{+} \mathrm{T}$ cells in the spleen and peritoneal cavity and B220 $\mathrm{B}$ cells in the spleen (Figure 2, D-G). DT was administered in 2 doses at 48 -hour intervals at $25 \mathrm{ng} / \mathrm{g}$ body weight and cell number assessed 24 hours later. Unlike previous DTR ablation models (25), the CD11b construct gave insufficient GFP signal for FACS analysis.

As expected, the F4/80-positive peritoneal population was unaffected in wild-type mice receiving 2 doses of DT (Figure 2D) but was eliminated in CD11b-DTR mice (Figure 2E). Importantly, in CD11b-DTR mice with complete peritoneal macrophage elimination, the $\mathrm{CD} 3^{+}$peritoneal cavity $\mathrm{T}$ cells were unaffected (Figure $2 \mathrm{E}$ ). The relative increase in $\mathrm{CD}^{+}$and double-negative cells in the DTtreated CD11b-DTR mice is due to the plotting of equal numbers of events. $\mathrm{B} 220^{+}$and $\mathrm{CD}^{+}$populations in the spleen were unaffected in either wild-type (Figure 2F) or CD11b-DTR mice (Figure 2G).

Because the endogenous CD11b gene is expressed in both macrophages and granulocytes, we determined which of the cell 

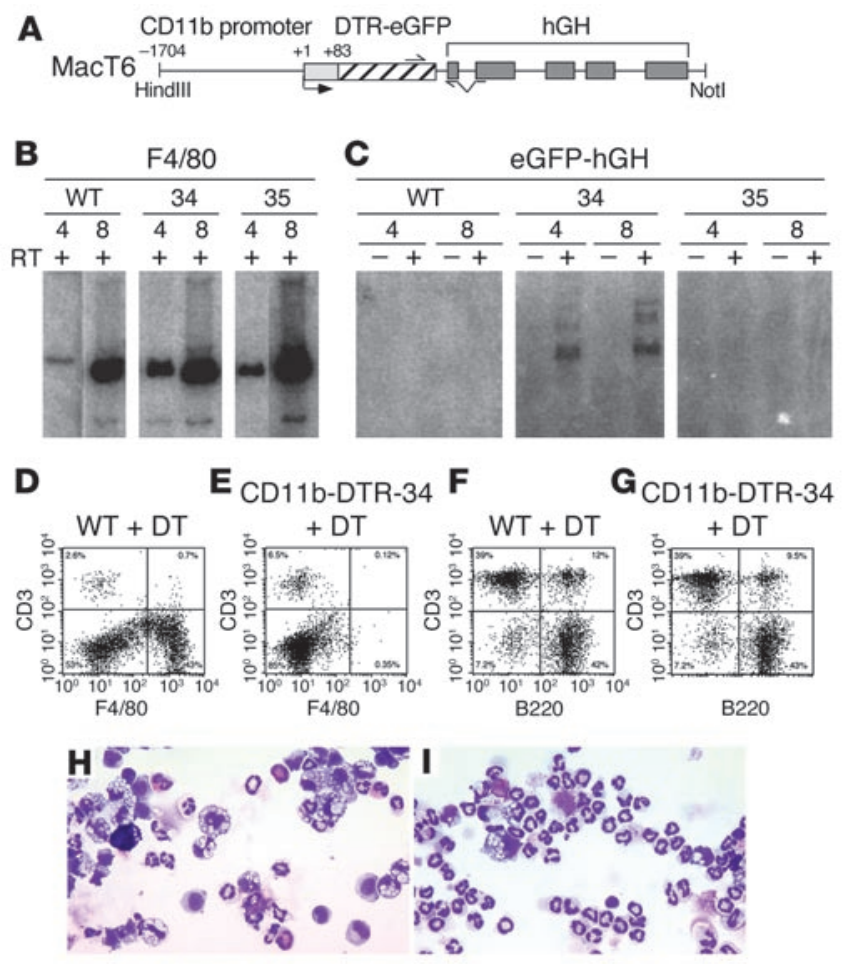

types recruited to the peritoneal cavity by injections of sterile Brewer's thioglycollate (BTG) could be killed by subsequent injections of DT. In CD11b-DTR homozygotes, BTG was injected 6 hours prior to injection of DT at $25 \mathrm{ng} / \mathrm{g}$ mouse weight and cells harvested for analysis 24 hours later. A morphological analysis showed that cells of monocyte/macrophage, eosinophil, neutrophil, basophil, and lymphocyte morphology were present in control mice (Figure $2 \mathrm{H}$ and Table 1 ) and that cells of monocyte/macrophage morphology only were greatly reduced in those treated with DT (Figure 2I and Table 1). It was particularly striking that most BTGelicited, DT-treated peritoneal cells were neutrophils (Figure 2I). Importantly, this showed that granulocytes were not sensitive to DT. Furthermore, blood leukocytes from DTR mice 24 hours following a single i.v. injection of DT revealed a selective depletion of F4/80-positive monocytes from $6.5 \% \pm 3.3 \%$ to $1.5 \% \pm 1.3 \%$.

DT effectively depletes SAMs. A model of $\mathrm{CCl}_{4}$-mediated liver fibrosis similar to that used in the rats was induced in CD11bDTR mice. At 11 weeks of $\mathrm{CCl}_{4}$ intoxication, the disease group of mice received 2 further doses of $\mathrm{CCl}_{4}$ and 3 macrophage-depleting doses of DT (or PBS as control) over the 12th week. Livers were harvested at the end of 12 weeks and assessed for SAMs. At peak fibrosis (12 weeks), control livers (treated with PBS and $\mathrm{CCl}_{4}$ ) exhibited extensive macrophage infiltration in and

\section{Figure 2}

Structure of the CD11b-DTR transgene and ablation specificity. (A) Diagram representing the MacT6 construct. The cDNA for the DTR-eGFP fusion gene is inserted between the human CD11b promoter (coordinates $-1,704$ to +83 relative to transcription start) and human growth hormone $(\mathrm{hGH})$ sequence that provides splicing and polyadenylation sequences. Small half-arrows indicate location of the nucleotide pair used for RT-PCR transcript detection; right-facing arrow, transcription start point; gray boxes, exons; and open boxes, untranslated regions. RT-PCR analysis performed on BM-derived macrophages for the control F4/80 (B) and transgenic DTR-eGFP (C) transcripts. Results shown for WT mice and CD11b-DTR lines 34 (positive-line example) and 35 (negative-line example). The eGFP-hGH oligonucleotide pair specifically amplified the transgene mRNA; amplification products were not evident in samples from WT mice or when reverse transcriptase (RT) was omitted. (D-G) FACS assessment of peritoneal and spleen populations. (D) In WT mice, injection of 2 doses of DT at $25 \mathrm{ng} / \mathrm{g}$ mouse weight does not affect either the small population of $\mathrm{CD}^{+} \mathrm{T}$ cells (upper left quadrant) or the larger population of $\mathrm{F} 4 / 80^{+}$macrophages (lower right quadrant) in the peritoneal cavity. (E) In heterozygous CD11bDTR mice receiving $D T$, the $\mathrm{F} 4 / 80^{+}$population is eliminated while the $\mathrm{CD}^{+}$cells remain. Neither the $\mathrm{CD}^{+}$nor the $\mathrm{B}^{2} 2 \mathrm{O}^{+}$cells in the spleen were affected by DT injection either in WT (F) or CD11b-DTR mice (G). Wright-Geimsa-stained cytospin preparations of BTG-elicited peritoneal cells after DTmut $(\mathbf{H})$ or DT (I) injection into CD11b-DTR mice. Normal proportions of elicited peritoneal cells were observed with injection of DTmut, but the absence of macrophages and preponderance of neutrophils was apparent in mice treated with DT.

surrounding the scar (Figure 3, A and E), which was markedly attenuated in both the treatment groups (DT and $\mathrm{CCl}_{4}$ ) (Figure $3, \mathrm{~B}$ and $\mathrm{E})$. We went on to establish a model to determine the phenotype of livers in which macrophages were depleted at the onset of spontaneous resolution. After 12 weeks of $\mathrm{CCl}_{4}$-mediated injury, another cohort of mice was allowed to recover spontaneously for 1 week. Forty-eight hours following the final injection of $\mathrm{CCl}_{4}$, mice received DT (or control PBS) for 5 days, and then livers were assessed for SAMs. This period of recovery covers the first 7 days when most of the loss of scar was seen in our previous rat and mouse recovery models. In the control-treated recovery group, SAMs could be seen by F4/80 staining (Figure 3, $\mathrm{C}$ and $\mathrm{F}$ ). The total number of SAMs had declined markedly after 7 days of recovery $(3.2 \% \pm 1.7 \%$ area) compared with peak fibrosis $(18 \% \pm 3.8 \%$ area $)$ in control mice. However, administration of DT by either route during recovery led to an approximately $50 \%$ reduction in SAMs at 7 days of recovery (Figure 3F). Our sample time in recovery was determined to maximize potential differences in matrix degradation and scar resolution. This necessarily meant harvest at a time point when most of the SAMs were lost from control livers. Consequently, a significant difference in overall SAM number was not seen in DT-treated relative to control mice at this time point.

Table 1

The effect of DT on peritoneal cell subtypes elicited with BTG

$\begin{array}{llccccc}\text { TreatmentA } & \begin{array}{l}\text { Monocytes/ } \\ \text { macrophage }\end{array} & \text { Basophils } & \begin{array}{c}\text { Polymorphs } \\ \text { Eosinophils }\end{array} & \text { Neutrophils } & \text { Lymphocytes } & \text { Mast cells } \\ \text { BTG/DTmut } & 33 \pm 1.9(54 \%) & 1.1 \pm 0.5(1.8 \%) & 2.6 \pm 0.4(4.3 \%) & 21 \pm 2.7(35 \%) & 1.8 \pm 0.5(3.0 \%) & 1.0 \pm 0.8(2.0 \%) \\ \text { BTG/DT } & 8.1 \pm 0.9(14 \%) & 2.0 \pm 0.7(3.4 \%) & 1.5 \pm 0.2(2.5 \%) & 44 \pm 3.7(75 \%) & 2.3 \pm 0.4(3.9 \%) & 0.9 \pm 0.3(1.5 \%)\end{array}$

${ }^{A} A$ single i.p. injection of DT at $25 \mathrm{ng} / \mathrm{g}$ mouse weight 6 hours after i.p. injection of $4 \mathrm{ml}$ of $4 \%$ BTG in PBS. 

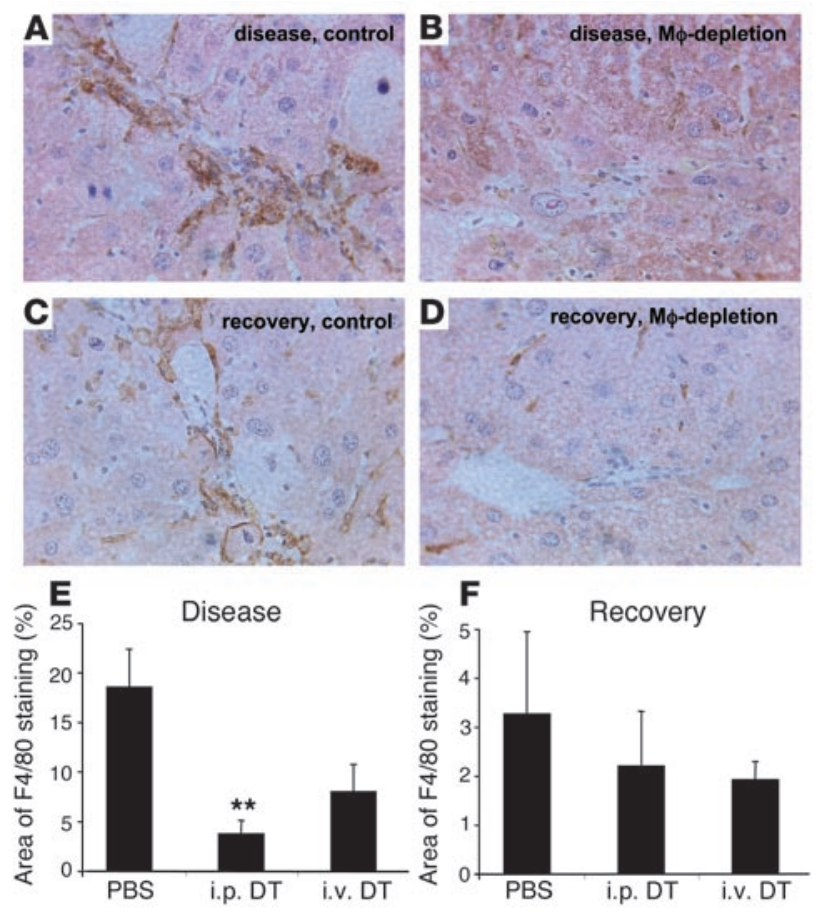

SAMs promote matrix deposition and support HSCs during injury. Livers depleted of SAMs during $\mathrm{CCl}_{4}$ injury were assessed for matrix components. Picrosirius red staining highlights polymeric and monomeric collagen matrix (29). Liver sections were assessed for the area of sirius red (Figure 4, A and E). Macrophage depletion markedly reduced sirius red. Sections were stained for collagen III, a representative fibrillar collagen secreted in excess in liver fibrosis (Figure 4, $\mathrm{C}$ and $\mathrm{G}$ ). Macrophage depletion also resulted in substantial reduction in the amount of this abnormal collagen. Another component of mature scar tissue that may promote matrix cross-linking is elastin (30). Depletion of macrophages leads to marked reduction of elastin at 12 weeks compared with that in controls (Figure 4, D and $\mathrm{H})$. Thus, each representative component of the scar matrix examined was substantially reduced during progressive liver injury in the absence of SAMs, indicating that SAMs either directly or indirectly promote the expression of matrix proteins and/or regulate the maintenance of abnormal extracellular matrix.

Because the collagens and elastin are produced primarily by myofibroblast HSCs $(9,31)$, we wondered whether the profound effect of SAMs on the pattern of fibrosis was via regulation of the HSC population. The number of $\alpha$-SMA-positive cells in the scars was assessed (Figure 4, B and F). Macrophage depletion by administration of DT either i.p. or i.v. led to a marked reduction in the number of HSCs. This indicates that SAMs support the activated HSC (myofibroblast) population, and, at least in part via this mechanism, promote fibrosis. We have previously determined that the population of HSCs is determined by the balance of proliferation and apoptosis (32). Therefore, BrdU uptake in scar cells was assessed in all livers (Table 2). During SAM depletion, the number of prolifer-

\section{Figure 3}

The effect of DT treatment on SAMs in CD11b-DTR mouse liver at peak fibrosis and after 7 days of spontaneous recovery. (A-D) Photomicrographs (magnification, $\times 400$ ) showing $(\mathbf{A})$ macrophages $(\mathrm{M} \phi)$ associated with areas of scarring after 12 weeks of $\mathrm{CCl}_{4}$-induced injury; (B) absence of macrophages in an area of scarring at 12 weeks of $\mathrm{CCl}_{4}$ injury, following 5 days of macrophage depletion; (C) macrophages associated with resolving fibrotic band, at 7 days of recovery from $\mathrm{CCl}_{4}$ injury; and (D) absence of macrophages in scar following macrophage depletion during spontaneous recovery. (E and F) Area of macrophage in fibrotic bands (E) at peak fibrosis following treatment with i.v. PBS, i.p. DT or i.v. DT, or (F) after 7 days of spontaneous recovery after treatment with i.v. PBS, i.p. DT, or i.v. DT $\left({ }^{\star \star} P<0.01\right)$.

ating scar-associated cells was markedly reduced, suggesting that SAMs directly induce HSC proliferation. The number of scar-associated apoptotic cells was also decreased following depletion of SAMs (Table 2). Therefore, SAMs may regulate both proliferation and apoptosis of myofibroblast HSCs.

SAMs promote the resolution of fibrosis during recovery. Livers depleted of SAMs during recovery were assessed for matrix components. Sirius red material decreased by $85 \%$ in control (PBStreated) mice after recovery compared with control mice at peak fibrosis (PBS and $\mathrm{CCl}_{4}$ ) (Figure 5, A and E). However, those mice with depletion of SAMs induced by i.p. or i.v. administration of DT during recovery had persistence of sirius red material, increasing from $1 \%$ of the biopsy to more than $3 \%$ of the biopsy. While the overall thickness of the bands of fibrosis had reduced during recovery in spite of SAM depletion, the most prominent feature was a persistence of perisinusoidal fibrosis in the absence of SAMs (Figure 5C). The amount of perisinusoidal fibrosis was assessed using an established scoring system (33) and was found to persist at a comparable level to peak fibrosis in the tissue from recovering livers as a result of depletion of SAMs (Table 2). The increase in perisinusoidal fibrosis score from 1.0 to 1.9 as a result of SAM depletion compares with a score of 2.5 at peak fibrosis in the control diseased mice. Thus, there is very little attenuation of perisinusoidal fibrosis in the absence of SAMs. Therefore, in stark contrast to the function of SAMs during $\mathrm{CCl}_{4}$ injury, SAMs during recovery promote degradation and resorption of matrix components. To be sure that this resorption included complex scar-associated matrix proteins, both collagen III (Figure 5, C and $\mathrm{G}$ ) and elastin (Figure 5, D and $\mathrm{H}$ ) were assessed. There was $50 \%$ more collagen III in livers from mice depleted of SAMs during recovery (predominantly due to a failure to resorb the perisinusoidal fibrosis). Elastin, a durable component of scar tissue, declined in response to recovery. However, following depletion of SAMs, there was no evidence of a reduction in elastin content.
Table 2

The effect of macrophage depletion on proliferation, apoptosis, and perisinusoidal fibrosis

\begin{tabular}{lrrrrrrr}
\hline & \multicolumn{3}{c}{$\begin{array}{c}\text { Injury } \\
\end{array}$} & \multicolumn{1}{c}{ Recovery } \\
& Control & i.p. DT & i.v. DT & Control & i.p. DT & i.v. DT \\
Scar-associated cells per 50 hpf & & & & & & \\
$\quad$ BrdU+ & $142 \pm 47^{\mathrm{A}}$ & $47 \pm 5$ & $57 \pm 3$ & $8.8 \pm 6.7$ & $16.7 \pm 3.1$ & $9.7 \pm 2.9$ \\
$\quad$ TUNEL+ & $43 \pm 17^{\mathrm{A}}$ & $9 \pm 3$ & $12 \pm 5$ & $3.4 \pm 2.3$ & $4.5 \pm 2.5$ & $3.7 \pm 2.5$ \\
Perisinusoidal fibrosis score & $2.5 \pm 0.9$ & & & $1.0 \pm 1.2^{\mathrm{B}}$ & $1.8 \pm 0.8$ & $1.9 \pm 0.7$
\end{tabular}

AMean \pm SEM; $P<0.01$ by ANOVA. BMean $\pm 95 \%$ confidence interval; $P<0.05$ by Wilcoxon rank sum test. 
A
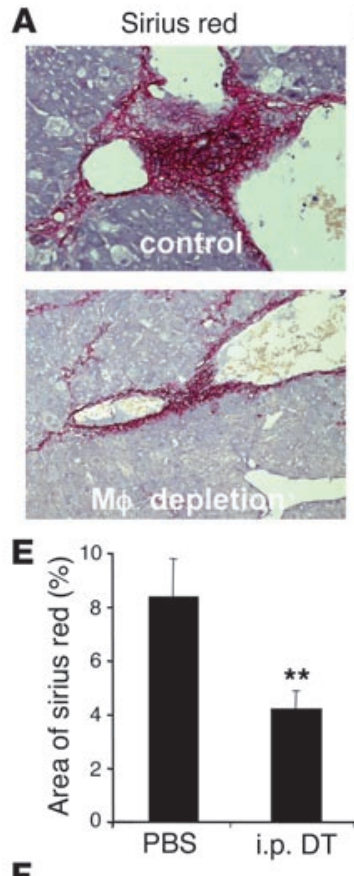

$\mathbf{F}$
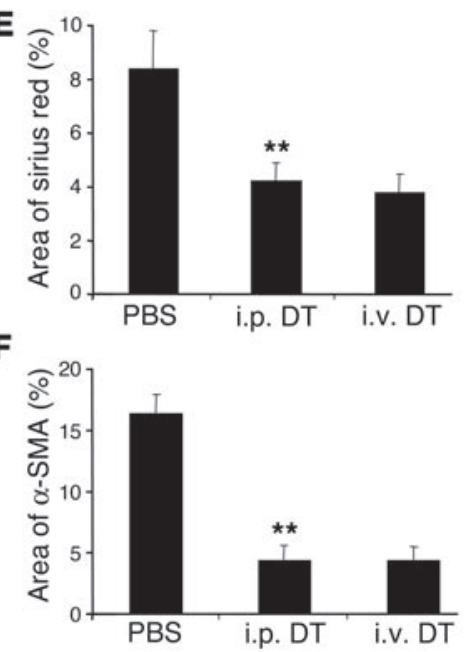

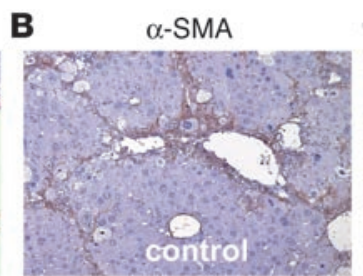

C
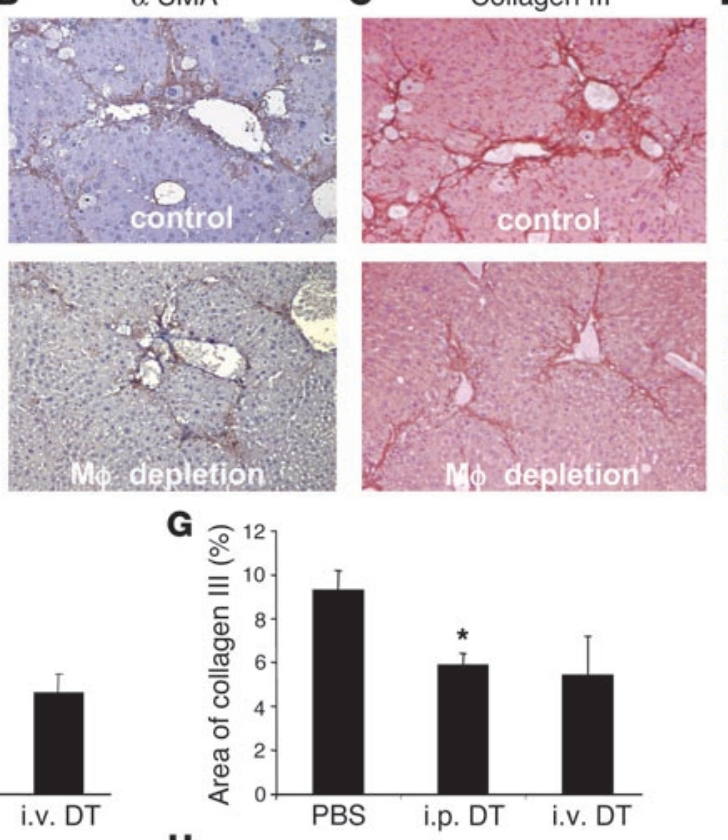

H

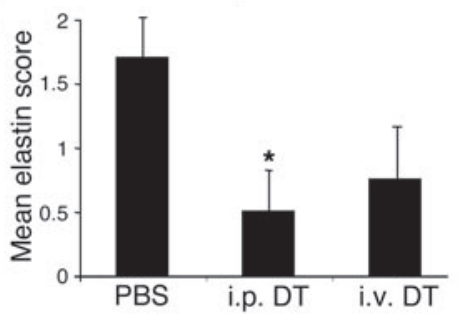

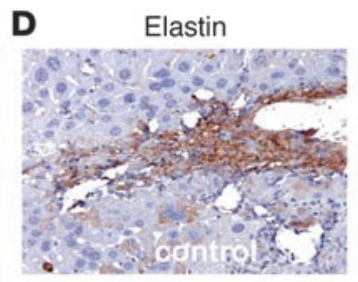

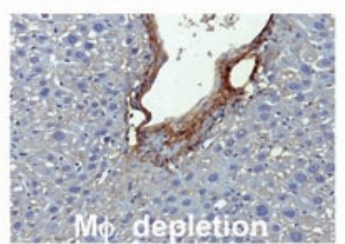

Figure 4

Components of the fibrotic response at peak fibrosis following $\mathrm{CCl}_{4}$ injury in the CD11b-DTR mouse, from control and macrophage-depleted animals. (A) Sirius red staining (magnification, $\times 200$ ) at 12 weeks after $\mathrm{CCl}_{4}$ injury with no depletion or macrophage depletion. Note extensive perisinusoidal fibrosis that is lost with macrophage depletion. (B) Extensive $\alpha$-SMA-positive HSCs (magnification, $\times 200$ ) in the fibrotic bands are seen with no depletion but not following macrophage depletion. (C) Collagen III staining (magnification, $\times 100$ ) showing both fibrotic bands and perisinusoidal fibrosis with no depletion and following depletion. (D) Elastin staining (magnification, $\times 200$ ) with no depletion or macrophage depletion. Macrophage depletion during $\mathrm{CCl}_{4}$ injury results in $(\mathbf{E})$ a reduction of sirius red staining and $(\mathbf{F})$ a reduction of area of $\alpha-S M A-$ positive HSCs. (G) Collagen III and $(\mathbf{H})$ elastin are reduced in fibrotic matrix following macrophage depletion $\left({ }^{*} P<0.05,{ }^{* *} P<0.01\right)$.

Thus, SAMs during recovery mediate opposite effects on matrix components and fibrosis compared with SAMs during injury. Both macrophages and activated HSCs can liberate a range of matrixdegrading MMP enzymes and regulate their activity via expression of TIMPs. Moreover, matrix degradation in spontaneous recovery from fibrosis is associated with a loss of activated HSCs (33), which are known to be quantitatively the major source of matrix (9). We therefore set out to determine whether the persistence of scar matrix during recovery in macrophage-depleted mice was due to persistence of myofibroblast-like activated HSCs. The area of $\alpha$-SMA cells during recovery was assessed in the presence of SAMs or following SAM depletion. Although there was a trend toward persistence of $\alpha$-SMA cells (Figure 5, B and F), this was not significant. Furthermore, when proliferation and apoptosis were assessed in the scars, no clear difference was seen (Table 2).

SAMs derive from both circulating monocytes and resident cells of the liver. In the liver there are 2 potential sources of SAMs. One derives from the circulating pool of BM-derived monocytes, and the other from the population of resident liver macrophages, the Kupffer cells. Because we had determined that 2 functional subsets of macrophages exist in liver injury, it was important to determine what role the Kupffer cells played in the disease process. To date, no phenotypic marker has been described that distinguishes Kupffer cells from monocyte-derived macrophages. We therefore took advantage of the observation that Kupffer cells in healthy livers of mice chimeric for BM cells are not replaced by BMderived cells after 8 weeks of chimerism (data not shown). Thus, the population of Kupffer cells can be distinguished from monocyte macrophages in BM chimeric mice. In female mice with male BM, SAMs in livers following 12 weeks of liver injury were assessed for the presence of the $\mathrm{Y}$ chromosome using established scoring methods (Figure 6) (34). In 5 - $\mu \mathrm{m}$ tissue sections, $28.3 \% \pm 4.2 \%$ of SAMs contained the Y chromosome, indicating that $45.7 \% \pm 6.8 \%$ of SAMs were derived from the BM-derived monocyte pool (see Methods for details). These data indicate that 2 populations of macrophages exist: 1 derived from monocytes, the other derived from a nonhematogenous source. It is likely that the second population derives from resident Kupffer macrophages.

SAMs during disease are phenotypically distinct from macrophages during recovery. We have demonstrated that SAMs during disease are 
Table 3

Relative expression of cytokine transcripts in whole liver during disease and recovery

\begin{tabular}{lcc}
\hline & & \\
tnfa & Disease & Recovery \\
il-10 & $1.82 \pm 0.54$ & $0.13 \pm 0.05$ \\
tgfß1 & $0.005 \pm 0.001$ & $0.002 \pm 0.0002$ \\
& $0.33 \pm 0.16$ & $1.04 \pm 0.4$ \\
\hline
\end{tabular}

Expression is relative to GAPDH. $n=4$ per group. Data are expressed as mean $\pm \mathrm{SEM}$.

functionally distinct from SAMs during recovery. It was important to determine whether a phenotypic marker could be elucidated. Analysis of tissue sections stained with macrophage markers CD11b, CD68 (data not shown), and F4/80 (Figure 3) unveiled no differences in macrophage expression during disease and recovery. In vitro studies of BM macrophages have shown that macrophages can be polarized into distinct cell types that are distinguished by expression of TNF- $\alpha$, IL-10, and TGF- $\beta 1$ (11). We used a quantitative RT-PCR method to determine the amounts of tnf $\alpha$ and $i l-10$ transcripts during injury and repair (Table 3). Previous studies have shown that RNA levels correlate closely with protein levels for these cytokines (35). During injury, tnf $\alpha$ transcript was 14-fold more abundant than during recovery (Table 3). During injury, il-10 transcript was also expressed more abundantly than during recovery, though the differences were less marked. Furthermore, $\operatorname{tnf} \alpha$ transcript was 360 -fold more abundant than $i l-10$. These data suggest that SAMs during injury express high levels of TNF- $\alpha$ and little IL-10, but that SAMs during recovery express little TNF- $\alpha$ and little IL-10. Although total tgf $\beta 1$ transcript was not significantly altered between disease and recovery (Table 3), tg $\beta$ 1 transcript levels have been shown not to correlate well with protein product (36), and TGF- $\beta 1$ expression is not limited to macrophages or immune cells. Liver sections were therefore immunolabeled for TGF- $\beta 1$ expression using a well-validated antibody (37). In scars of active disease we found abundant expression of TGF- $\beta 1$ in cells of the scar (morphologically the source cells were inflammatory cells and activated HSCs/myofibroblasts), extracellular matrix, and cells with the morphology of hepatocytes immediately adjacent to the scars (Figure 7A). Sections labeled with control rabbit IgG revealed no specific binding (data not shown). In contrast TGF- $\beta 1$ was absent from the scars during recovery (Figure 7B). When SAMs were depleted during injury, the scars also did not express TGF- $\beta 1$,

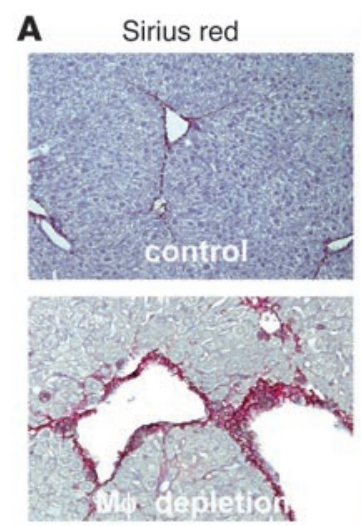

E

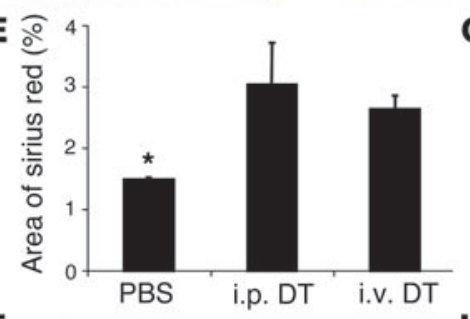

F

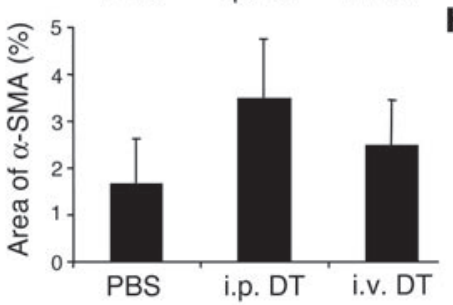

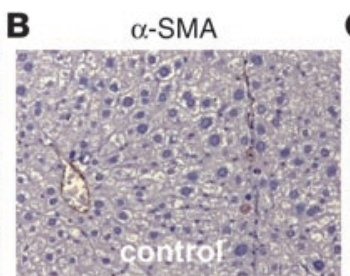

C
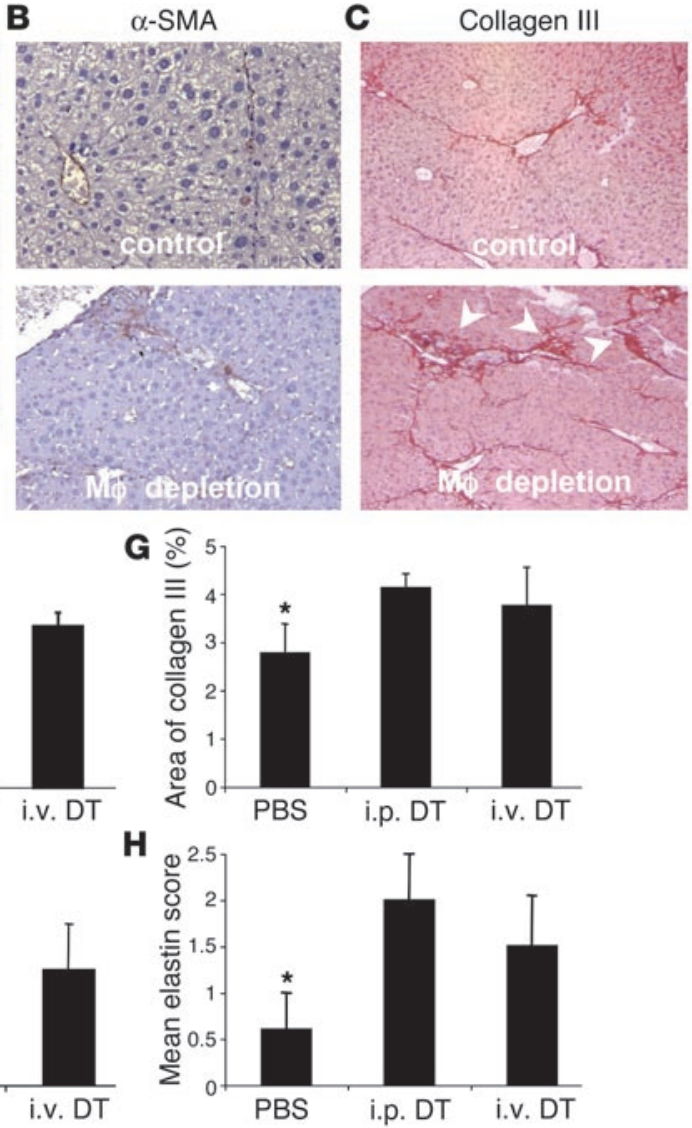

D Elastin
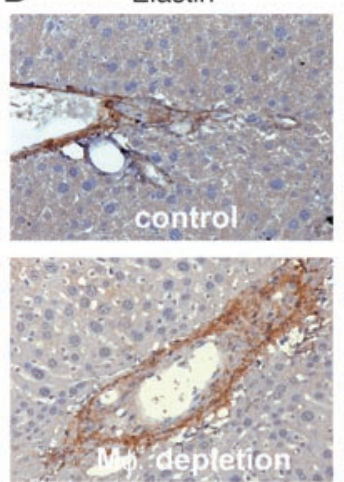

Figure 5

Components of the resolving fibrosis after 7 days of spontaneous recovery from $\mathrm{CCl}_{4}$-induced injury in control and macrophage-depleted CD11b-DTR mice. (A) Sirius red-positive material (magnification, $\times 100$ ) following 7 days of recovery with no depletion or macrophage depletion. Note extensive loss of fibrotic bands and perisinusoidal fibrosis. (B) $\alpha$-SMA-positive HSCs (magnification, $\times 200$ ) in the liver after 7 days of recovery with no depletion or macrophage depletion. (C) Collagen III staining (magnification, $\times 100$ ) following 7 days of recovery with no depletion or macrophage depletion. Note persistence of perisinusoidal fibrosis (arrowheads). (D) Elastin staining (magnification, $\times 200$ ) with no depletion or macrophage depletion. Macrophage depletion during recovery results in (E) persistence of the total area of fibrosis detected by sirius red staining but (F) nonsignificant persistence of $\alpha$-SMA-positive HSCs. Depletion of macrophage during recovery results in persistence of $(\mathbf{G})$ excess collagen III and $(\mathbf{H})$ elastin ( $\left.{ }^{\star} P<0.05\right)$. 


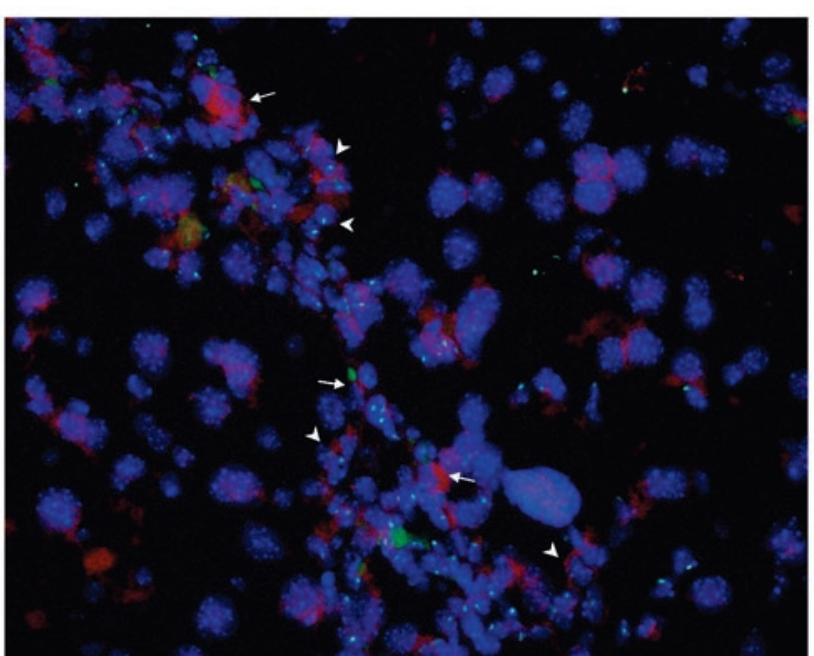

Figure 6

Y chromosome-positive SAMs after 12 weeks of liver injury in female $\mathrm{BALB} / \mathrm{c}$ mice chimeric for male BM (magnification, $\times 600$ ). F4/80-labeled macrophages (red) are located in the region of a scar. Y chromosomeFITC hybridization (green) can be seen in nuclei labeled with DAPI (blue). Note macrophages with nuclei containing Y-chromosomal DNA (arrowheads) and also macrophages without $Y$-chromosomal DNA (arrows).

though expression could still be seen in cells with the morphology of hepatocytes (data not shown). Furthermore, when SAMs were depleted during recovery, TGF- $\beta 1$ expression was still not seen in scars. Taken together, these observations indicate that SAMs during injury not only express TGF- $\beta 1$, but also likely induce expression in other cells of the scar, including HSCs, whereas the SAMs present after the onset of recovery do not express this cytokine.

\section{Discussion}

To assess macrophage function at distinct phases of disease and recovery, we developed a novel system for depletion of macrophages during disease. The role of the inflammatory tissue macrophage has remained a subject of debate, at least in part because macrophages are associated with both tissue injury and repair (10). In addition, when macrophages have been depleted in a series of injury models, the results have been conflicting $(38,39)$. Macrophage have been successfully depleted during induction of several animal models of inflammatory diseases by antimacrophage serum or by administration of liposomal clodronate $(1,3,4,10,40)$. While both undoubtedly deplete macrophages, the former has pleiotropic effects, and the latter has been complicated by neutrophil depletion, toxicity, and ineffective depletion in some tissues $(40,41)$. To circumvent these difficulties, we developed a novel transgenic mouse in which minute injections of DT can deplete macrophages. This is possible because the mouse equivalent of the DT receptor (hbEGF) binds DT very poorly; mice are therefore insensitive to DT (27) while tissue-specific expression of the human DT receptor confers sensitivity $(25,26)$.

We have now shown that the deletion of the macrophage population either during injury or during repair and resolution has dramatically different effects on the overall fibrotic response. Specifically, in progressive inflammatory injury, macrophage depletion results in amelioration of fibrosis. By contrast, depletion during recovery results in a failure of resolution with persistence of cellular and matrix components of the fibrotic response. These data represent the first definitive demonstration that macrophages play distinct roles in injury and repair and highlight the critical observation that a given cell may be both pathogenic and beneficial.

Our experiments suggest that over a period of a few days, 2 functionally distinct types of macrophages exist in the injured liver. During the injury phase (a time when chemokines, complement components, and proinflammatory cytokines are abundant) injury-associated macrophages promote myofibroblast proliferation and apoptosis. On balance, macrophages have the effect of increasing myofibroblast numbers. As a result, fibrogenesis predominates and matrix is deposited. The phenotype of macrophages associated with the injury phase is closest to that of the aa-Ms described by others (11). However, it is present in response to injury normally associated with classically activated macrophages, as it is present at a stage when proinflammatory cytokines are released.

In contrast, during recovery from injury, a population of macrophages predominates that does not support HSC survival and promotes matrix degradation and, in that regard, resembles classically activated macrophages. This macrophage population, however, is present during resolution of injury and at a time when proinflammatory mediator levels are decreasing, an observation reinforced by our studies of TNF- $\alpha$ in this model. Moreover, these 2 functional phenotypes are separated chronologically in the liver by only a few days, suggesting that they may represent a single population. Therefore, we suggest that the yin and yang of the classically activated macrophage/aa-M model is inadequate to reflect the complex roles of these cells in vivo during liver injury.

In our study, the SAMs during injury are associated with high expression of TGF- $\beta 1$ in the scars and high levels of liver tnf $\alpha$ transcript. In contrast, during recovery, SAMs are not associated with TGF- $\beta 1$ generation in the scars, and the liver tnf $\alpha$ transcript is attenuated. We have identified 2 sources of SAMs. One is monocyte-derived, and the other is derived from a nonhematogenous source. It is likely that this other source of SAMs is the resident liver macrophages, the Kupffer cells. It is tempting to speculate as to whether one functional population of macrophages derives from monocytes and the other from Kupffer cells. Further experiments (beyond the scope of the current study) will be required to determine whether the functional distinctions are clearly related to macrophage origin.

Our study indicates that SAMs during disease are associated with high levels of proliferation and apoptosis in the scars, but that these
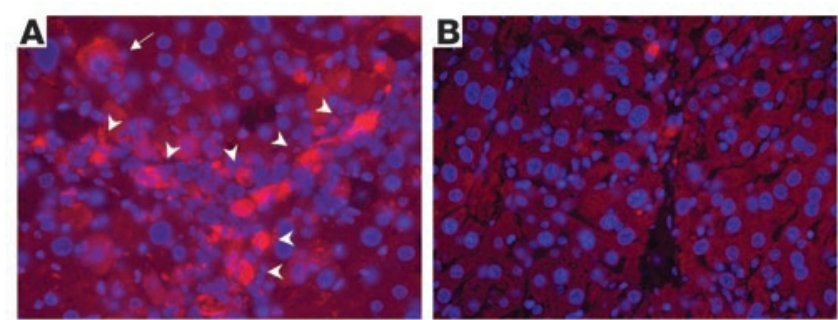

\section{Figure 7}

TGF- $\beta$ expression in the fibrotic bands (magnification, $\times 400$ ). (A) After 12 weeks of disease in the mouse model, fibrotic bands (denoted by arrowheads) contain numerous cells showing immunofluorescence for TGF- $\beta$. In addition, cells with the morphology of hepatocytes also express cytoplasmic TGF- $\beta$ (arrow). (B) Following 7 days of recovery from injury, the fibrotic bands show no evidence of TGF- $\beta$ expression. In addition, no hepatocytes show TGF- $\beta$ expression. 
parameters are markedly decreased by depletion of SAMs. Thus, the SAMs may induce both proliferation and apoptosis and, as such, maintain a population of HSC myofibroblasts. Macrophages are known to induce cell cycle-dependent cell death in some settings (42), and so there is reason to consider this mechanism of cell number regulation in the injured liver. Furthermore, macrophages can liberate both potent myofibroblast growth factors, such as PDGF, and proapoptotic factors, such as TNF- $\alpha$. Indeed, SAMs during disease generate TNF- $\alpha$. Our data reveal that after 7 days of recovery, apoptosis and proliferation in the scars is reduced and the population of HSC myofibroblasts is much reduced. Thus, SAMs during recovery do not share these characteristics with SAMs during disease. In a previous study, we have shown that the loss of HSCs during recovery in rats is due to a wave of apoptosis occurring predominantly in the first 3 days (7). We do not see this wave of apoptosis in the current study, in which we focused on 7 days of recovery in order to demonstrate changes in matrix components. It is likely that the wave of apoptosis occurred at an earlier time point.

Previous studies using other methods to modify or deplete macrophages have pointed to a role for macrophages in mediating the fibrotic response $(4,39)$. Those studies have been inconsistent, however, which may reflect nonspecific depletion of other cell types or the existence of distinct functional populations of macrophages in the different models of inflammation and scarring that were studied. Our new conditional ablation system is nontoxic, is cell type-specific, is effective in many tissues, and offers the possibility of time pointselective deletion of cells during a range of inflammatory processes.

We suggest that our description of the roles of macrophages in functional terms should provide the basis for a series of future functional studies in vivo to define more accurately the nature, specific attributes, and dynamics of the macrophage population(s) present in inflammation and repair. We further suggest that a description of macrophage populations based on functional studies in vivo should form the basis of a rational and clinically relevant classification of the cell.

\section{Methods}

\section{Materials}

All reagents were from Sigma-Aldrich unless stated otherwise. DT and mutant DT (DT $\left.{ }^{\mathrm{mut}}\right)$, which lacks intracellular enzyme activity, were from List Biological Laboratories Inc. Animals were housed in a standard sterile animal facility with free access to chow and water. All manipulations and procedures were undertaken with approved license from the Animal Scientific Procedures Division of the Home Office (London, UK).

\section{Transgenic construct}

The $C D 11 b$ promoter from coordinates $-1,704$ to +83 (28) was used to drive expression of the human hbEGF cDNA(27). Splicing and polyadenylation signals were provided by a region of the human growth hormone gene that had previously worked effectively with the CD11b promoter (28). The fusion protein between hbEGF and GFP was generated by continuing the open reading frame of hbEGF at the final residue with the open reading frame of GFP at residue 1. The transgene fragment was excised using the HindIII and NotI restriction endonucleases and purified using standard techniques. The CD11b-DTR construct was used to generate transgenic mice (43) using conventional techniques (44). Transgene expression was detected using an RT-PCR assay. The primer sequences used were AAGATCCGCCACAACATCG for the $5^{\prime}$ primer and GCAGCTCTAGGTTGGATTTCTG for the $3^{\prime}$ primer. No PCR product could be amplified from genomic DNA.

\section{FACS analysis}

Mouse peritoneal and spleen cells were isolated using conventional methods (35). Blood leukocytes were purified from heparinized blood by centrifugation followed by aspiration of buffy coat. The latter was washed 3 times in PBS to remove platelets. Remaining erythrocytes were removed by hypotonic lysis on ice, followed by further PBS washes. A total of $2 \times 10^{6}$ cells were preincubated with FACS buffer containing Fc Block (BD Biosciences - Pharmingen). Fifty microliters of FACS buffer containing FITC- or PE-conjugated anti-B220, anti-CD3 (BD Biosciences - Pharmingen), or anti-F4/80 (Serotec) was then added and incubated at $4^{\circ} \mathrm{C}$ for 1 hour. Cells were washed 3 times in FACS buffer and fixed in $2 \%$ formaldehyde in PBS prior to analysis.

\section{Disease models}

Progressive fibrosis demonstrating complete spontaneous recovery. $\mathrm{CCl}_{4}$ liver fibrosis was induced in Sprague-Dawley rats by twice weekly i.p. injections of $\mathrm{CCl}_{4}$ in sterile olive oil (7). After 4 weeks, cohorts of animals were allowed to spontaneously recover for periods of up to 28 days (7).

Advanced fibrosis and micronodular cirrbosis. $\mathrm{CCl}_{4}$ liver fibrosis was induced and analyzed after 6 weeks (fibrosis) and 12 weeks (advanced micronodular cirrhosis). Cohorts were allowed to recover for 28 days (9, 24). The more advanced cirrhosis demonstrated a reduced capacity for spontaneous resolution. Nevertheless, there was considerable remodeling during the recovery period.

Mouse model of hepatic fibrosis and spontaneous recovery from fibrosis in DTR mice. Twenty-four adult DTR mice (FVB/N) were injected with $0.25 \mu \mathrm{l} / \mathrm{g}$ of $\mathrm{CCl}_{4}$ i.p. twice weekly for 12 weeks. During the 12th week, half the mice (disease group) were given either (a) DT (10 ng/g i.v. by tail vein) immediately following the first injection of $\mathrm{CCl}_{4}$ that week, DT (i.v.) 24 hours later, and DT (i.v.) a further 48 hours later to coincide with the next injection of $\mathrm{CCl}_{4}$; (b) DT $(25 \mathrm{ng} / \mathrm{g}$ i.p.) over a similar schedule; or (c) $100 \mu$ PBS (i.v.) as control to coincide with the DT injections. During the 13th week, the remaining mice (recovery group) did not receive any further $\mathrm{CCl}_{4}$ injections. However, 72 hours following the final $\mathrm{CCl}_{4}$ injection, mice were given either (a) DT (10 ng/g i.v.), DT (i.v.) 24 hours later, and DT (i.v.) a further 48 hours later; (b) DT (25 ng/g i.p.) over a similar schedule; or (c) $100 \mu \mathrm{l}$ PBS (i.v.) to coincide with the DT injections. Livers were harvested 24 hours following the final dose of DT or PBS.

\section{Mouse BM transplant model to trace the lineage of the SAMS}

In order to trace the lineage of the SAMs, we performed sex-mismatched BM transplants from male donor mice into female recipients, which allowed us to detect male BM-derived SAMs through in situ hybridization for the $\mathrm{Y}$ chromosome combined with immunostaining for F4/80 antigen. Six-weekold female recipient $\mathrm{BALB} / \mathrm{c}$ mice $(n=7)$ underwent whole-body, lethal $\gamma$ irradiation (8 Gray) in divided doses. This was followed by a tail vein injection with whole BM from 3 male BALB/c donors. Femurs from the male donors were removed and marrow was flushed with PBS using a needle syringe. The product was filtered twice through a 70-micron tube filter and centrifuged to purify the cells. One million BM cells were resuspended in $200 \mu \mathrm{l}$ of PBS and injected i.v. into each recipient female on the same day. Four weeks later, liver fibrosis was induced by repeated $\mathrm{CCl}_{4}$ injection for 12 weeks as described above, and tissue was collected 72 hours following the last $\mathrm{CCl}_{4}$ injection.

\section{Immunostaining}

Rat SAMs were detected in 3- $\mu \mathrm{m}$ paraffin-embedded sections using ED-1 antibody (Serotec) as previously described (45). $\alpha$-SMA was detected by incubation with 1A4 antibody (DAKO) as previously described (7). Mouse SAMs were detected in 3- $\mu \mathrm{m}$ methyl Carnoys-fixed paraffin-embedded sections using anti-F4/80 antibody (46), except for the tissue analysis requiring in situ hybridization, where $5-\mu \mathrm{m}$ formalin-fixed sections were digested with trypsin 
at $37^{\circ} \mathrm{C}$ for 20 minutes prior to the immunodetection. Collagen III was detected by incubating sections with anticollagen III (Southern Biotech) as described (47). Elastin was detected by antielastin antibody (Cedar Lane Labs), followed by secondary stages of immunostaining as previously described (7). TGF- $\beta 1$ was detected in formalin-fixed sections using anti-mouse TGF- $\beta 1$ antibodies, followed by donkey anti-rabbit Cy3-conjugated secondary antibody (Jackson Laboratories). Immunolabeled sections were mounted in Vectorshield with DAPI. For detection of SAMs prior to in situ hybridization, tissue sections were incubated with rat anti-F4/80 (Abcam), followed by biotinylated antirat antibodies and streptavidin-alkaline phosphatase (DAKO), and immunodetection completed with Vector Red substrate (Vector Laboratories). All other liver sections were counterstained with hematoxylin, H\&E, or picrosirius red as appropriate. To measure proliferation, mice were injected with BrdU (Boehringer Manheim) $(50 \mu \mathrm{g} / \mathrm{g})$ i.p. 2 hours prior to harvesting of livers. Sections were incubated with anti-BrdU (Serotec) as described (48). To assess apoptosis, TUNEL staining was performed using commercial products (Oncogene Research Products) as described $(7,49)$.

\section{In situ hybridization technique}

Following the immunodetection of F4/80, sections were incubated in 1 $\mathrm{M}$ sodium thiocyanate for 10 minutes at $80^{\circ} \mathrm{C}$, washed in PBS, and then digested in pepsin $(0.4 \% \mathrm{wt} / \mathrm{vol})$ in $0.1 \mathrm{M} \mathrm{HCl}$ at $37^{\circ} \mathrm{C}$ for 12 minutes. The protease was quenched in glycine $(0.2 \% \mathrm{wt} / \mathrm{vol})$ in $2 \times \mathrm{PBS}$, and then sections were rinsed in PBS, postfixed in paraformaldehyde (4\% wt/vol) in PBS, dehydrated through graded alcohols, and air dried. FITC-labeled Y-chromosome paint (Star-FISH; Cambio) was used in the supplier's hybridization mix, added to the sections, sealed under glass with rubber cement, heated to $80^{\circ} \mathrm{C}$ for 10 minutes and incubated overnight at $37^{\circ} \mathrm{C}$. The slides were rinsed in $0.5 \times$ SSC and then in PBS. Slides were mounted in DAPI/Citifluor prior to fluorescent microscopy.

\section{Assessment of tissue sections}

Rat SAMs were scored as number per high-power field (hpf). An ED-1-positive cell was included if it was within or apposed to the scar. Rat $\alpha$-SMApositive cells were counted as previously described (7). Mouse SAMs were assessed morphometrically using Fovea Pro 3.5 software (Reindeer Graphics) to quantify the area of tissue occupied by positive staining (47). At least 10 serial images were taken of the tissue section $(\times 100)$, covering the whole tissue section. Collagen III immunostaining was assessed morphometrically for percentage area of liver occupied by collagen III matrix. Picrosirius redstained sections and $\alpha$-SMA-stained sections were assessed morphometrically by the same method. In addition, because computerized morphometry cannot distinguish fibrotic bands from perisinusoidal fibrosis, the latter was scored blindly by an established scoring system where +4 is established cirrhosis, +3 is advanced fibrosis, +2 is early bridging fibrosis, and +1 is early pericellular fibrotic changes (33). Due to the relatively low levels of elastin deposition, this was also scored using a similar blinded scoring method ranging from 0-4 (33). Whole tissue sections were assessed blindly for BrdU ${ }^{+}$ nuclei and $\mathrm{TUNEL}^{+}$cells in scar tissue as previously described $(7,45,48)$. To determine the origins of SAMs, F4/80-staining SAMs were considered to be of $\mathrm{BM}$ origin if the nucleus also contained a green fluorescent region due to the presence of Y-chromosomal DNA as previously described (34). Because not all SAMs in the section will exhibit the nucleus, tissue sections from male mice with the same disease were prepared in the same way and scored for the proportion of SAMs with nuclei containing Y-chromosomal DNA. Using this score $(62.0 \%)$ as a maximum, the proportion of SAMs of male origin in the chimeras was calculated.

\section{Real time RT-PCR}

RNA was purified from diseased livers using the RNAeasy kit (Qiagen). In brief, tissue was homogenized in a buffer containing guanidine isothiocyanate and then passed over a silica-based gel that selectively binds RNA. Purified RNA was eluted following washing of the gel. Following DNase treatment, cDNA was generated from $1 \mathrm{ng}$ of whole RNA using iScript cDNA synthesis kit (BioRad Laboratories), which relies on a combination oligo (dT) and random hexamers for annealing and an $\mathrm{RNase} \mathrm{H}+$ reverse transcriptase for accurate synthesis. cDNA was analyzed for content using a SYBR green-based, quantitative fluorescent PCR method (Qiagen). Fluorescence was detected with the iCycler system (BioRad Laboratories). The following primer pairs were used for detection of specific cDNAs: GAPDH, 5'-CTGAGAAACCTGCCAAGTA-3', 5'-AAGAGTGGGAGTTGCTGTTG-3'; TNF- $\alpha, 5^{\prime}$-CGCTCTTCTGTCTACTGAACTT-3', 5'-GATGAGAGGGAGGCCATT-3'; IL-10, 5'-CAGCCTTGCAGAAAAGAGAG-3', 5'-GGAAGTGGGTGCAGTTATTG-3'; TGF- $\beta$, CTCCACCTGCAAGACCAT-3', $5^{\prime}$-CTTAGTTTGGACAGGATCTGG-3'. Each assay was performed in duplicate a $25-\mu 1$ reaction volume with $2 \times$ SYBR green mastermix, $1 \mu \mathrm{l}$ of cDNA, and primers at $300 \mathrm{nM}$. The following PCR conditions were used: $95^{\circ} \mathrm{C}$ for 15 minutes, followed by 45 cycles of $94^{\circ} \mathrm{C}$ for 15 seconds, $50^{\circ} \mathrm{C}$ for 30 seconds, and $72^{\circ} \mathrm{C}$ for 30 seconds, followed by $72^{\circ} \mathrm{C}$ for a final 10 minutes. Each PCR reaction was also tested to assure a single product of the predicted size. Quantification of each PCR product was expressed relative to GAPDH.

\section{Statistics}

Difference between percentage area measured morphometrically was expressed as mean \pm SEM and assessed by ANOVA. Allotted scores were expressed as mean $\pm 95 \%$ confidence intervals and assessed using Wilcoxon ranked sum method.

\section{Acknowledgments}

We thank J.S. Savill, J. Hughes, J.-F. Calhier, and K. Simpson (University of Edinburgh); J.V. Bonventre (Harvard Medical School); and F. Russo (Imperial College) for assistance. J.S. Duffield is supported by a Senior Fellowship from the National Kidney Research Fund, United Kingdom. S.J. Forbes is a Wellcome Advanced Fellow. J.P. Iredale gratefully acknowledges the support of the Medical Research Council, United Kingdom, Children's Liver Disease Foundation (United Kingdom), and the Wessex Medical Trust.

Received for publication July 9, 2004, and accepted in revised form November 2, 2004.

Address correspondence to: Jeremy Duffield, Renal Division, 5th Floor, Brigham and Women's Hospital, Harvard Institutes of Medicine, 77 Avenue Louis Pasteur, Boston, Massachusetts 02115, USA. Phone: (617) 525-5914; Fax: (617) 525-5830; E-mail: jduffield@rics.bwh.harvard.edu.

\footnotetext{
1. Leibovich, S.J., and Ross, R. 1975. The role of the macrophage in wound repair. A study with hydrocortisone and antimacrophage serum. Am.J. Pathol. 78:71-100.

2. Kodelja, V., et al. 1997. Differences in angiogenic potential of classically vs alternatively activated macrophages. Immunobiology. 197:478-493.

3. Danenberg, H.D., et al. 2002. Macrophage deple-
}

tion by clodronate-containing liposomes reduces neointimal formation after balloon injury in rats and rabbits. Circulation. 106:599-605.

4. Zhang-Hoover, J., Sutton, A., van Rooijen, N., and Stein-Streilein, J. 2000. A critical role for alveolar macrophages in elicitation of pulmonary immune fibrosis. Immunology. 101:501-511.

5. Tsunawaki, S., Sporn, M., Ding, A., and Nathan, C.
1988. Deactivation of macrophages by transforming growth factor-beta. Nature. 334:260-262.

6. Diez-Roux, G., and Lang, R.A. 1997. Macrophages induce apoptosis in normal cells in vivo. Development. 124:3633-3638.

7. Iredale, J.P., et al. 1998. Mechanisms of spontaneous resolution of rat liver fibrosis. Hepatic stellate cell apoptosis and reduced hepatic expression 
of metalloproteinase inhibitors. J. Clin. Invest. 102:538-549.

8. Desmouliere, A., Darby, I.A., and Gabbiani, G. 2003. Normal and pathologic soft tissue remodeling: role of the myofibroblast, with special emphasis on liver and kidney fibrosis. Lab. Invest. 83:1689-1707.

9. Murphy, F.R., et al. 2002. Inhibition of apoptosis of activated hepatic stellate cells by tissue inhibitor of metalloproteinase- 1 is mediated via effects on matrix metalloproteinase inhibition: implications for reversibility of liver fibrosis. J. Biol. Chem. 277:11069-11076.

10. Duffield, J.S. 2003. The inflammatory macrophage: a story of Jekyll and Hyde. Clin. Sci. 104:27-38.

11. Goerdt, S., and Orfanos, C.E. 1999. Other functions, other genes: alternative activation of antigenpresenting cells. Immunity. 10:137-142.

12. Mariani, T.J., Sandefur, S., Roby, J.D., and Pierce, R.A. 1998. Collagenase-3 induction in rat lung fibroblasts requires the combined effects of tumor necrosis factor-alpha and 12-lipoxygenase metabolites: a model of macrophage-induced, fibroblast-driven extracellular matrix remodeling during inflammatory lung injury. Mol. Biol. Cell. 9:1411-1424.

13. Song, E., et al. 2000. Influence of alternatively and classically activated macrophages on fibrogenic activities of human fibroblasts. Cell. Immunol. 204:19-28.

14. Buechler, C., et al. 2000. Regulation of scavenger receptor CD163 expression in human monocytes and macrophages by pro- and anti-inflammatory stimuli. J. Leukoc. Biol. 67:97-103.

15. Willment, J.A., et al. 2003. Dectin-1 expression and function are enhanced on alternatively activated and GM-CSF-treated macrophages and are negatively regulated by IL-10, dexamethasone, and lipopolysaccharide. J. Immunol. 171:4569-4573.

16. Zhang, Y., McCluskey, K., Fujii, K., and Wahl, L.M. 1998. Differential regulation of monocyte matrix metalloproteinase and TIMP-1 production by TNFalpha, granulocyte-macrophage CSF, and IL-1 beta through prostaglandin-dependent and -independent mechanisms. J. Immunol. 161:3071-3076.

17. Pierce, R.A., Sandefur, S., Doyle, G.A., and Welgus, H.G. 1996. Monocytic cell type-specific transcriptional induction of collagenase. J. Clin. Invest. 97:1890-1899.

18. Fadok, V.A., et al. 1998. Macrophages that have ingested apoptotic cells in vitro inhibit proinflammatory cytokine production through autocrine/paracrine mechanisms involving TGF- $\beta$, PGE2, and PAF. J. Clin. Invest. 101:890-898.

19. Erwig, L.P., Kluth, D.C., Walsh, G.M., and Rees, A.J. 1998. Initial cytokine exposure determines function of macrophages and renders them unresponsive to other cytokines. J. Immunol. 161:1983-1988.

20. Mantovani, A., Sozzani, S., Locati, M., Allavena, P., and Sica, A. 2002. Macrophage polarization: tumor-associated macrophages as a paradigm for polarized M2 mononuclear phagocytes. Trends Immunol. 23:549-555.

21. Raes, G., et al. 2002. FIZZ1 and Ym as tools to discriminate between differentially activated macrophages. Dev. Immunol. 9:151-159.

22. Cattell, V., Largen, P., de Heer, E., and Cook, T. 1991. Glomeruli synthesize nitrite in active Heymann nephritis; the source is infiltrating macrophages. Kidney Int. 40:847-851.

23. Duffield, J.S., Ware, C.F., Ryffel, B., and Savill, J. 2001. Suppression by apoptotic cells defines tumor necrosis factor-mediated induction of glomerular mesangial cell apoptosis by activated macrophages. Am. J. Pathol. 159:1397-1404.

24. Issa, R., et al. 2004. Spontaneous recovery from micronodular cirrhosis: evidence for incomplete resolution associated with matrix cross-linking. Gastroenterology. 126:1795-1808.

25. Jung, S., et al. 2002. In vivo depletion of CD11c(+) dendritic cells abrogates priming of CD8 $(+) \mathrm{T}$ cells by exogenous cell-associated antigens. Immunity. 17:211-220.

26. Saito, M., et al. 2001. Diphtheria toxin receptormediated conditional and targeted cell ablation in transgenic mice. Nat. Biotechnol. 19:746-750.

27. Naglich, J.G., Metherall, J.E., Russell, D.W., and Eidels, L. 1992. Expression cloning of a diphtheria toxin receptor: identity with a heparin-binding EGFlike growth factor precursor. Cell. 69:1051-1061.

28. Dziennis, S., et al. 1995. The CD11b promoter directs high-level expression of reporter genes in macrophages in transgenic mice. Blood. 85:319-329.

29. Junqueira, L.C., Bignolas, G., and Brentani, R.R. 1979. Picrosirius staining plus polarization microscopy, a specific method for collagen detection in tissue sections. Histochem. J. 11:447-455.

30. Maki, J.M., et al. 2002. Inactivation of the lysyl oxidase gene Lox leads to aortic aneurysms, cardiovascular dysfunction, and perinatal death in mice. Circulation. 106:2503-2509.

31. Theret, N., Lehti, K., Musso, O., and Clement, B. 1999. MMP2 activation by collagen I and concanavalin A in cultured human hepatic stellate cells. Hepatology. 30:462-468.

32. Iredale, J.P. 2001. Hepatic stellate cell behavior during resolution of liver injury. Semin. Liver Dis. 21:427-436.

33. Issa, R., et al. 2003. Mutation in collagen-1 that confers resistance to the action of collagenase results in failure of recovery from CCl4-induced liver fibrosis, persistence of activated hepatic stellate cells, and diminished hepatocyte regeneration. FASEB J. 17:47-49.

34. Forbes, S.J., et al. 2004. A significant proportion of myofibroblasts are of bone marrow origin in human liver fibrosis. Gastroenterology. 126:955-963.

35. Stuart, L.M., et al. 2002. Inhibitory effects of apoptotic cell ingestion upon endotoxin-driven myeloid dendritic cell maturation. J. Immunol.
168:1627-1635.

36. McDonald, P.P., Fadok, V.A., Bratton, D., and Henson, P.M. 1999. Transcriptional and translational regulation of inflammatory mediator production by endogenous TGF-beta in macrophages that have ingested apoptotic cells. J. Immunol. 163:6164-6172.

37. Morath, C., et al. 2001. Effects of retinoids on the TGF-beta system and extracellular matrix in experimental glomerulonephritis. J. Am. Soc. Nephrol. 12:2300-2309.

38. Jose, M.D., Ikezumi, Y., van Rooijen, N., Atkins, R.C., and Chadban, S.J. 2003. Macrophages act as effectors of tissue damage in acute renal allograft rejection. Transplantation. 76:1015-1022.

39. Westerhuis, R., et al. 2000. Distinctive roles of neutrophils and monocytes in anti-thy- 1 nephritis. Am. J. Pathol. 156:303-310.

40. Feith, G.W., et al. 1997. Decreased PMN accumulation and glomerular damage by clodronate liposome treatment in PMN-dependent anti-GBM nephritis in mice. Exp. Nephrol. 5:301-304.

41. Van Rooijen, N., and Sanders, A. 1996. Kupffer cell depletion by liposome-delivered drugs: comparative activity of intracellular clodronate, propamidine, and ethylenediaminetetraacetic acid. Hepatology. 23:1239-1243.

42. Diez-Roux, G., Argilla, M., Makarenkova, H., Ko, K., and Lang, R.A. 1999. Macrophages kill capillary cells in G1 phase of the cell cycle during programmed vascular regression. Development. 126:2141-2147.

43. Taketo, M., et al. 1991. FVB/N: an inbred mouse strain preferable for transgenic analyses. Proc. Natl. Acad. Sci. U. S. A. 88:2065-2069.

44. Hogan, B., Costantini, F., and Lacy, E. 1986. Manipulating the mouse embryo: a laboratory manual. Cold Spring Harbor Laboratory Press. Cold Spring Harbor, New York, USA. 332 pp.

45. Baker, A.J., et al. 1994. Mesangial cell apoptosis: the major mechanism for resolution of glomerular hypercellularity in experimental mesangial proliferative nephritis. J. Clin. Invest. 94:2105-2116.

46. Morris, L., Graham, C.F., and Gordon, S. 1991. Macrophages in haemopoietic and other tissues of the developing mouse detected by the monoclonal antibody F4/80. Development. 112:517-526.

47. Ophascharoensuk, V., et al. 1999. Obstructive uropathy in the mouse: role of osteopontin in interstitial fibrosis and apoptosis. Kidney Int. 56:571-580.

48. Hughes, J., and Johnson, R.J. 1999. Role of Fas (CD95) in tubulointerstitial disease induced by unilateral ureteric obstruction. Am. J. Physiol. 277:F26-F32.

49. Stahelin, B.J., Marti, U., Solioz, M., Zimmermann, H., and Reichen, J. 1998. False positive staining in the TUNEL assay to detect apoptosis in liver and intestine is caused by endogenous nucleases and inhibited by diethyl pyrocarbonate. Mol. Pathol. 51:204-208. 